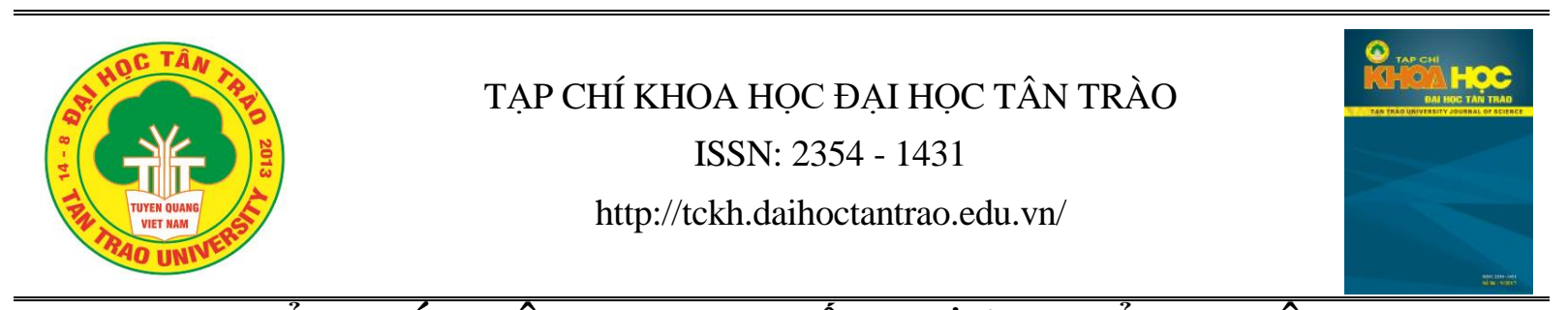

\title{
GIẢI PHÁP NÂNG CAO CHẤT LỰ̛̣G ĐẢNG VIỂN Ở ĐẢNG BỘ TRƯỜNG ĐẠI HỌC TÂN TRÀO
}

\author{
Phạm Mạnh Hàa ${ }^{a^{*}}$, Đàm Thị Thanh Thủy ${ }^{a}$, Trần Thị Thanh Vân ${ }^{a}$ \\ ${ }^{a}$ Trường Đại học Tân Trào \\ *Email:manhhatq2009@gmail.com
}

\section{Thông tin bài viết}

Ngày nhận bài:

26/3/2020

Ngày duyệt đăng:

$10 / 6 / 2020$

Tù khóa:

Đảng viên; chất luợng

đảng viên, giải pháp nâng

cao chất luợng đảng viên

\section{Tóm tắt}

Nâng cao chất lượng đảng viên có tầm quan trọng đặc biệt, không chỉ là nền tảng để xây dựng, củng cố đội ngũ đảng viên, còn tác động đến uy tín, đến năng lực lãnh đạo của Đảng. Bài báo phân tích làm rõ thực trạng công tác đánh giá chất lượng đảng viên ở Đảng bộ Trường Đại học Tân Trào và đề xuất giải pháp cơ bản nâng cao chất lượng đảng viên ở Đảng bộ Trường Đại học Tân Trào.

\section{1. Đặt vấn đề}

Chủ tịch Hồ Chí Minh khẳng định: “Để lãnh đạo cách mạng, Đảng phải mạnh. Đảng mạnh là do chi bộ tốt. Chi bộ tốt là do các đảng viên đều tốt" [6]. Do vậy, nâng cao chất lượng đội ngũ đảng viên là nội dung quan trọng để nâng cao chất lượng hoạt động của các tổ chức cơ sở Đảng, là cốt lõi để xây dựng Đảng. Xác định rõ vấn đề này, một trong những giải pháp mà Nghị quyết Trung ương 4 (khóa XII) đã đề ra là "rà soát, sàng lọc và đưa ngay những người không còn đủ tư cách đảng viên ra khỏi Đảng”. Cụ thể hóa Nghị quyết Trung ương 4 (khóa XII), ngày 21-1-2019, Ban Bí thư đã ban hành Chỉ thị số 28$\mathrm{CT} / \mathrm{TW}$ về nâng cao chất lượng kết nạp đảng viên và rà soát, sàng lọc, đưa những đảng viên không còn đủ tư cách ra khỏi Đảng [1].

Đảng bộ Trường Đại học Tân Trào có 18 chi bộ trực thuộc với 187 đảng viên. Đội ngũ đảng viên có bản lĩnh chính trị, lập trường tư tưởng vững vàng; có phẩm chất đạo đức tốt, lối sống lành mạnh; thực hiện đúng các quy định về những điều đảng viên không được làm, về phòng, chống tham nhũng, lãng phí; phát huy tinh thần đoàn kết; luôn sẵn sàng nhận nhiệm vụ được giao; tích cực hưởng ứng các phong trào thi đua... Việc đánh giá chất lượng hằng năm thực hiện theo quy định của Ban Thường vụ Tỉnh ủy, Ban Thường vụ Đảng ủy khối các cơ quan tỉnh về kiểm điểm, đánh giá, xếp loại chất lương tổ chức đảng, tập thể cấp ủy, đảng viên. Số đảng viên được đánh giá hoàn thành tốt nhiệm vụ trở lên hằng năm đạt trên $85 \%$. Để nâng cao chất lượng đảng viên của Đảng bộ Trường Đại học Tân Trào, phải thường xuyên rà soát, sàng lọc đội ngũ đảng viên. Đây là nhiệm vụ quan trọng, thường xuyên, là yêu cầu khách quan và cũng là vấn đề có tính quy luật trong công tác xây dựng Đảng, góp phần nâng cao chất lượng đội ngũ cán bộ, đảng viên trong toàn Đảng bộ và có ý nghĩa cấp thiết trong giai đoạn hiện nay.

2. Thực trạng công tác đánh giá chất lượng đảng viên ở Đảng bộ Trường Đại học Tân Trào

\subsection{Công tác giáo dục, rèn luyện đảng viên}

Đảng bộ thường xuyên chú trọng công tác tuyên truyền giáo dục cho đảng viên về chủ nghĩa Mác - Lênin, tư tưởng Hồ Chí Minh. Đẩy mạnh và thực hiện tốt các 
cuộc vận động “Hai không”, cuộc vận động: "Mỗi thầy cô giáo là một tấm gưong tụ học, tụ sáng tạo" đặc biệt tích cực học tập và làm theo tư tưởng, tấm gương đạo đức, phong cách Hồ Chí Minh theo tinh thần Chỉ thị số 05CT/TW ngày 15/5/2016 của Bộ Chính trị gắn với các chuyên đề hằng năm. Thường xuyên tổ chức cho đảng viên học tập các chủ trương đường lối, Chỉ thị, Nghị quyết của Đảng, chú trọng công tác đào tạo, bồi dưỡng nâng cao trình độ lý luận và chuyên môn nghiệp vụ cho đảng viên, đặc biệt là đảng viên mới kết nạp. Đảng viên luôn gương mẫu đi đầu trong học tập, công tác, lôi cuốn được quần chúng tin tưởng, noi theo.

Quán triệt đầy đủ các chủ trương, nghị quyết, chỉ thị, quy định về xây dựng, phát triển đội ngũ đảng viên. Trên cơ sở đó, các chi bộ đã tập trung lãnh đạo, chỉ đạo, xây dựng những kế hoạch, giải pháp cụ thể, phù hợp với đặc điểm, yêu cầu nhiệm vụ để thực hiện, nhằm tăng cường xây dựng, củng cố, phát triển tổ chức cơ sở đảng, xây dựng hệ thống chính trị và nâng cao chất lượng đội ngũ cán bộ, đảng viên. Do đó, đội ngũ đảng viên đã không ngừng phát triển cả về số lượng và chất lượng; cơ cấu đội ngũ đảng viên từng bước được chuyển biến theo hướng tích cực, bảo đảm sự lãnh đạo toàn diện của Đảng; tỷ lệ đảng viên trẻ, đảng viên nữ, đảng viên là sinh viên, đảng viên là người dân tộc thiểu số đều tăng lên qua các năm.

2.2. Công tác phát triển đảng viên mới và rà soát, sàng lọc, đưa nhũng người không đủ tư cách ra khỏi Đảng

Hằng năm Đảng ủy trường đã xây dựng kế hoạch phát triển đảng viên, chỉ đạo các chi bộ và các tổ chức đoàn thể: Công đoàn, Đoàn thanh niên, Hội sinh viên Nhà trường tích cực, bồi dưỡng, phân công, giúp đỡ, giao nhiệm vụ để thử thách cho các công đoàn viên, hội viên. Nhiệm kỳ 2010-2015, Đảng bộ Trường đã kết nạp được 47 đảng viên mới trong đó có 08 sinh viên [1]. Từ đầu nhiệm kỳ tháng 4 năm 2015 đến tháng 02 năm 2020 Đảng bộ Trường kết nạp được 95 đảng viên mới trong đó có 36 sinh viên. Riêng năm 2019 kết nạp được 18 đảng viên mới trong đó có 09 sinh viên [2]. Từ việc tăng cường công tác tạo nguồn bồi dưỡng, phát triển Đảng đã tạo ra phong trào thi đua sôi nổi trong học tập, rèn luyện, tỷ lệ sinh viên xếp loại khá giỏi ngày càng tăng. Qua khảo sát một số sinh viên là đảng viên khi ra Trường tìm được việc làm thể hiện được vai trò của người đảng viên ở đơn vị công tác mới.

Ban Thường vụ Đảng ủy Trường Đại học Tân Trào luôn xác định việc rà soát, sàng lọc và kịp thời đưa những người không còn đủ tư cách đảng viên ra khỏi Đảng là việc làm cần thiết, góp phần nâng cao năng lực lãnh đạo và sức chiến đấu của tổ chức đảng. Từ năm 2015 đến nay, toàn Đảng bộ có 01 đảng viên bị thi hành kỷ luật, bằng hình thức khiển trách; 01 đảng viên dự bị không đủ điều kiện chuyển đảng viên chính thức, phải xóa tên khỏi danh sách đảng viên [4].

\subsection{Về thụ̂c hiện nguyên tắc tổ chức xây dụng} Đảng

Trong nhiều năm qua, công tác xây dựng tổ chức cơ sở đảng trong sạch, vững mạnh được các chi bộ xác định là nhiệm vụ trọng tâm. Công tác đánh giá chất lượng tổ chức cơ sở đảng và đảng viên đã từng bước đi vào thực tiễn, tiêu chí và phương thức đánh giá được xây dựng và cụ thể hóa.

Đảng bộ trường thường xuyên quan tâm chỉ đạo việc kiểm điểm, đánh giá, xếp loại tổ chức cơ sở Đảng và đảng viên trên tinh thần quán triệt các văn bản hướng dẫn của Ban Thường vụ Trung ương và Tỉnh ủy. Việc khắc phục, sửa chữa những khuyết điểm, hạn chế sau kiểm điểm tự phê bình và phê bình của tổ chức cơ sở Đảng và đảng viên được gắn với thực hiện Chỉ thị 05 của Bộ Chính trị về "Đẩy mạh học tập và làm theo tu tưởng, đạo đức, phong cách Hồ Chí Minh".

Việc đánh giá chất lượng tổ chức cơ sở Đảng, đảng viên được cấp ủy chú trọng, có sự đổi mới mang tính xây dựng. Trong 5 năm, Đảng bộ Trường Đại học Tân Trào đã có 18 chi bộ đảng "Trong sạch, vũng mạnh tiêu biểu", 106 đảng viên "Hoàn thành xuất sắc nhiệm vụ" được khen thưởng. Riêng trong năm 2019 toàn Đảng bộ có 4/21 chi bộ đạt trong sạch, vững mạnh chiếm 19,04\%. [4].

\subsection{Về công tác đánh giá chất lự̛ng đảng viên}

Đánh giá, phân loại chất lượng đảng viên là việc làm thường xuyên hằng năm, là công việc quan trọng trong công tác xây dựng Đảng hiện nay. Thực hiện sự chỉ đạo của Ban Tổ chức Tỉnh ủy Tuyên Quang về việc kiểm điểm, đánh giá, xếp loại tập thể, cá nhân cán bộ lãnh đạo quản lý các cấp và đảng viên; đánh giá chất lượng tổ chức cơ sở đảng ở cơ sở [5]; với sự quan tâm lãnh đạo, chỉ đạo sát sao của Ban Thường vụ Đảng ủy khối các cơ quan tỉnh, công tác đánh giá, xếp loại cá nhân cán bộ lãnh đạo quản lý các cấp và đảng viên ở Đảng bộ Trường Đại học Tân Trào đã đạt được những kết quả tích cực.

Qua công tác đánh giá phân loại tổ chức đảng, đảng viên và cán bộ lãnh đạo quản lý năm từ năm 2015 đến nay cho thấy: Các chi bộ trực thuộc đã thực hiện việc đánh giá, phân loại chất lượng tổ chức cơ sở đảng và đảng viên 
gắn với việc đánh giá kết quả thực hiện nhiệm vụ chính trị của đơn vị, kết quả học tập và làm theo tấm gương, đạo đức, phong cách Hồ Chí Minh và Nghị quyết Trung ương 4 (khóa XII) về tăng cường xây dựng, chỉnh đốn Đảng; ngăn chặn, đẩy lùi sự suy thoái về tư tưởng chính trị, đạo đức, lối sống, những biểu hiện "tự diễn biến", "tự chuyển hóa" trong nội bộ. Phân loại chất lượng tổ chức cơ sở đảng và đảng viên đã góp phần nâng cao nhận thức tư tưởng về tính tổ chức, kỷ luật, sự nỗ lực phấn đấu của tổ chức đảng và đảng viên. Vì vậy, chất lượng tổ chức cơ sở đảng, đội ngũ cán bộ, đảng viên được đánh giá qua các năm đã có nhiều chuyển biến tích cực, đạt được kết quả thực chất hơn.

Năm 2019, qua phân tích, đánh giá chất lượng tổ chức cơ sở đảng và đảng viên của Đảng bộ Trường Đại học Tân Trào, kết quả có: 04 chi bộ xếp loại hoàn thành xuất sắc nhiệm vụ, chiếm 19,05\%; 17 chi bộ hoàn thành tốt nhiệm vụ, chiếm $80,95 \%$. Có 23 đảng viên hoàn thành xuất sắc nhiệm vụ, chiếm $12,37 \% ; 145$ đảng viên hoàn thành tốt nhiệm vụ, chiếm 77,96\%; 11 đảng viên hoàn thành nhiệm vụ, chiếm 5,91\%. Đảng bộ Trường không có tổ chức đảng xếp loại không hoàn thành nhiệm vụ [4] .

Bên cạnh những thành tựu đã đạt được, trong thời gian qua, công tác xây dựng đội ngũ đảng viên còn những hạn chế, yếu kém. Do đó, chất lượng đội ngũ đảng viên chưa đáp ứng được yêu cầu đặt ra. Đó là tình trạng một bộ phận cán bộ, đảng viên trong đó chưa thể hiện vai trò tiên phong gương mẫu, còn nói nhiều làm ít, hoặc nói nhưng không làm, tính chiến đấu, tinh thần đấu tranh tự phê bình và phê bình chưa cao; một bộ phận, muốn làm theo cách cũ, không chịu đổi mới; chưa quan tâm đúng mức đến công tác xây dựng Đảng.

\section{Giải pháp cơ bản nâng cao chất lượng đảng viên ở Đảng bộ Trường Đại học Tân Trào}

Từ thực trang đã phân tích trên, chúng tôi đề xuất một số giải pháp nâng cao chất lượng đảng viên ở Đảng bộ Trường Đại học Tân Trào như sau:

Thư nhất, đẩy mạnh công tác giáo dục, rèn luyện đảng viên. Chú trọng đổi mới nội dung, hình thức tuyên truyền, giáo dục, nâng cao ý thức cách mạng, bản lĩnh chính trị, đạo đức, lối sống cho công chức, viên chức, đảng viên và người lao động, đẩy mạnh tuyên truyền đến cán bộ, viên chức, đảng viên và người lao động về các chủ trương, đường lối của Đảng, chính sách, pháp luật của Nhà nước; việc học tập và làm theo tư tưởng, đạo đức, phong cách Hồ Chí Minh gắn với thực hiện Nghị quyết Trung ương 4 (khóa XI, khóa XII) về xây dựng, chỉnh đốn Đảng, Quy định số 101-QĐ/TW về trách nhiệm nêu gương của cán bộ, đảng viên, nhất là người đứng đầu. Mỗi cán bộ, viên chức, đảng viên và người lao động xây dựng kế hoạch rèn luyện, giữ gìn tư cách đạo đức, phẩm chất của cán bộ, đảng viên; chấp hành nghiêm Điều lệ Đảng, Quy định về "Những điều đảng viên không được làm"; nêu cao ý thức tu dưỡng, rèn luyện, học tập, đấu tranh chống chủ nghĩa cơ hội, thực dụng, vụ lợi cá nhân; chống tham nhũng, lãng phí, quan liêu, các biểu hiện tiêu cực khác...; kịp thời đấu tranh, ngăn chặn các luận điệu xuyên tạc, phản động để thực hiện âm mưu "diễn biến hòa bình" của các thế lực thù địch.

Thư hai, nâng cao bản lĩnh chính trị nhận thức về Đảng, vai trò, nhiệm vụ của tổ chức đảng, đảng viên. Để làm được điều đó, Đảng bộ Trường Đại học Tân Trào cần đổi mới nội dung giáo dục, hình thức, phương pháp công tác chính trị tư tưởng của các chi bộ, đảng bộ phải gắn với giáo dục lịch sử, truyền thống yêu nước, tăng cường tính đảng, xây dựng niềm tin vào sự nghiệp đổi mới đất nước.

Thư $b a$, nâng cao trình độ, năng lực chuyên môn. Hằng năm lập kế hoạch đào tạo, bồi dưỡng giảng viên theo từng giai đoạn. Khuyến khích giảng viên học thạc sĩ, tiến sĩ ở nước ngoài. Lựa chọn những sinh viên có học lực giỏi, ưu tiên những sinh viên - đảng viên được tiếp tục đào tạo sau đại học, trở thành giảng viên trong trường; động viên, khuyến khích đội ngũ đảng viên là giảng viên, chuyên viên, sinh viên tích cực phấn đấu vươn lên về mọi mặt.

Thú $t u$, thường xuyên thực hiện tự phê bình và phê bình để sàng lọc làm trong sạch đội ngũ đảng viên. Hằng năm, khi đánh giá chất lượng đảng viên các chi bộ cần chỉ rõ mặt mạnh để động viên, khuyến khích và mặt yếu để có biện pháp khắc phục. Khi phân tích chất lượng đảng viên cần chi tiết, sát thực để kết quả phân loại chính xác. Các đồng chí bí thư chi bộ, ban chi ủy phải gương mẫu thực hiện trước với tinh thần thẳng thắn và xây dựng. Sàng lọc, đưa ra khỏi Đảng những đảng viên không đủ tư cách.

Thư năm, tăng cường công tác phát triển đảng viên. Các chi bộ cần thống nhất nhận thức về vai trò, tầm quan trọng của công tác phát triển đảng viên và sự cần thiết đẩy mạnh công tác phát triển đảng viên ở tổ chức đảng của mình; đẩy mạnh công tác tuyên truyền, giáo dục nâng cao nhận thức cho cán bộ, đảng viên về vị trí, ý nghĩa, tầm quan trọng của công tác phát triển đảng viên trong giai 
đoạn hiện nay; chú trọng công tác tạo nguồn, bồi dưỡng cảm tình đảng và đặc biệt quan tâm đến đối tượng là đoàn viên, thanh niên; khi kết nạp đảng viên phải coi trọng cả về số lượng và chất lượng, người được kết nạp vào Đảng phải bảo đảm cả tiêu chuẩn và điều kiện theo quy định của Điều lệ Đảng, chú trọng tiêu chuẩn giác ngộ lý tưởng của Đảng, đạo đức, lối sống và năng lực hoàn thành nhiệm vụ được giao. Đồng thời, gắn trách nhiệm của các tổ chức đoàn thể trong trường với công tác phát triển đảng viên.

Thú sáu, phát huy vai trò của Đoàn thanh niên và Hội sinh viên. Hoạt động của Đoàn thanh niên và Hội sinh viên có ý nghĩa lớn trong xây dựng đảng và đội ngũ đảng viên. Mỗi đảng viên phải coi đây là trách nhiệm của mình, xây dựng Đoàn thanh niên và Hội sinh viên vững mạnh, tích cực giáo dục rèn luyện đoàn viên thanh niên, đặc biệt chú ý công tác phát triển đảng; bản thân đảng viên thật sự gương mẫu. Đoàn thanh niên và Hội sinh viên phải nhận thức đúng trách nhiệm, tự xây dựng vững mạnh về chính trị, tư tưởng; tổ chức tốt các hoạt động xung kích; tham gia xây dựng Đảng kịp thời. Tổ chức phong trào thi đua dạy tốt, học tốt, hoạt động văn hoá, văn nghệ, thể thao, tổ chức nhiều cuộc tọa đàm, đối thoại giữa tổ chức đảng, đảng viên lão thành với đảng viên trẻ, đoàn viên thanh niên theo các chủ đề "Tuổi trẻ với Đảng - Đảng với tuổi trẻ", "Tiếp lửa truyền thống mãi mãi tuổi hai mươi", Mời báo cáo viên về nói chuyện thời sự, thi tìm hiểu Tư tưởng Hồ Chí Minh... Chi bộ Quản lý sinh viên xây dựng chương trình giáo dục cho sinh viên ngay từ năm học đầu tiên bằng cách tổ chức "Tuần chính trị đầu khoá". Tổ chức cho đảng viên là sinh viên đi tham quan các di tích lịch sử có nhiều ý nghĩa giáo dục (Khu di tích lịch sử Tân Trào, Khu di tích lịch sử Kim Bình, Đền thờ Bác Hồ...).

Thư bẩy, thực hiện nghiêm việc đánh giá chất lượng đảng viên. Để tiếp tục triển khai, tổ chức thực hiện việc kiểm điểm, đánh giá, xếp loại chất lượng đảng viên đạt chất lượng hiệu quả đề ra, Đảng bộ trường tiếp tục quán triệt nâng cao nhận thức cho các chi bộ, đảng viên về mục đích ý nghĩa, tầm quan trọng và trách nhiệm của tập thể, cá nhân trong việc kiểm điểm, đánh giá, xếp loại chất lượng đối với đảng viên. Trong đó, cần đẩy mạnh thực hiện kiểm điểm tự phê bình và phê bình theo tinh thần Nghị quyết Trung ương 4 (khóa XII) gắn với học tập và làm theo tư tưởng, đạo đức, phong cách Hồ Chí Minh. Lấy kết quả thực hiện nhiệm vụ được giao; kết quả tự phê bình và phê bình; sự nêu gương của cán bộ lãnh đạo, quản lý; kết quả thực hiện cam kết rèn luyện, giữ gìn phẩm chất đạo đức, lối sống và hiệu quả đấu tranh khắc phục suy thoái "tự diễn biến", “tự chuyển hóa" là những tiêu chí quan trọng để đánh giá xếp loại hằng năm.

\section{Kết luận}

Qua tổng kết và đánh giá sơ bộ thực trạng công tác đánh giá chất lượng đảng viên ở Đảng bộ Trường Đại học Tân Trào, chúng tôi đã đề xuất bảy giải pháp cơ bản nâng cao chất lượng đảng viên ở Đảng bộ Trường Đại học Tân Trào. Việc thực hiện các giải pháp này một cách đồng bộ sẽ góp phần nâng cao chất lượng đảng viên ở Đảng bộ Trường Đại học Tân Trào, đây là một nhiệm vụ quan trọng giúp cho Đảng bộ nhà trường và các chi bộ trực thuộc thực hiện tốt nhiệm vụ xây dựng Đảng, xây dựng đội ngũ đảng viên nói riêng luôn trong sạch, vững mạnh, đáp ứng được yêu cầu nhiệm vụ chính trị đã đặt ra, giúp cho người quản lý xác định cho mình một hướng đi đúng đắn, biết xây dựng được biện pháp chỉ đạo quản lý phù hợp, để xây dựng được một tập thể sư phạm vững mạnh gắn bó với nghề, phấn đấu vì sự nghiệp giáo dục và đào tạo.

\section{TÀI LIỆU THAM KHẢO}

[1]. Chị thị số 28-CT/TW ngày 21 tháng 1 năm 2019, Chỉ thị của Ban Bí thư về nâng cao chất lượng kết nạp đảng viên và rà soát, sàng lọc, đưa những đảng viên không còn đủ tư cách ra khỏi Đảng.

[2]. Báo cáo tổng kết 2015, phương hướng 2016: 29BC/ĐU ngày 28/12/2015 của Đảng ủy Trường Đại học Tân Trào.

[3]. Báo cáo tổng kết 2019, phương hướng 2020: số 310-BC/ĐU ngày 27 tháng 12 năm 2019 của Đảng ủy Trường Đại học Tân Trào.

[4]. Báo cáo chính trị, Số 336-BC/ĐU ngày 02 tháng 3 năm 2020 của Đảng ủy Trường Đại học Tân Trào.

[5]. Ban Tổ chức Tỉnh ủy Tuyên Quang (2019), Hướng dẫn về kiểm điểm và đánh giá, xếp loại chất lượng hằng năm đối với tổ chức đảng, đảng viên và tập thể, cá nhân cán bộ lãnh đạo, quản lý các cấp.

[6]. Hồ Chí Minh toàn tập (2002), NXB CTQG, H.2002, tập 15, tr.113. 


\section{Improving the quality of party members at party committee of Tan Trao university in the new stage}

Pham Manh Ha, Dam Thi Thanh Thuy, Tran Thi Thanh Van

\begin{tabular}{l} 
Article info \\
\hline Recieved: \\
26/3/2020 \\
Accepted: \\
10/6/2020 \\
\hline
\end{tabular}

Keywords:

Party member; the quality of party members, solutions to improve the quality of party members.

\begin{abstract}
Improving the quality of party members is especially important, It is not only a foundation to build and strengthen the party members, but also affects the prestige and leadership of the Party. Improving the quality of party members is an important task to build a clean and strong Universty Party, contributing to improving the quality of human resources for society. In order to continuously improve the Party's capacity and fighting strength, it is necessary to build clean and strong party members with a strong political stance, revolutionary moral qualities and working capacity. Therefore, improving the quality of party members at the Party Committee of Tan Trao University in the new stage is necessary and practical.
\end{abstract}

